\title{
Intensity of in-seeing disabled population in Maharashtra State of India -Census 2001
}

\author{
Misrilal Bhadu Chavan \\ Pratap College, Amalner. Dist.Jalgaon (M.S), India.
}

Accepted 28 March, 2012

\begin{abstract}
As per the census of India about $1.62 \%$ population of Maharashtra state is found disabled. In the total disabled population of the state, the proportion of in-seeing disabled persons is ranked first. In rural areas, proportion of in-seeing disabled population is near about two times more than the urban areas. The proportion of in-seeing disabled males is also significantly higher than that of the females.Highest proportion and intensity of in-seeing disabled population is observed in Nandurbar and Nanded districts. Nandurbar is a tribal district located in Satpura mountainous region. Poor economic condition, mountainous region, imbalance diet to pregnant women and children are important causes of high proportion of in-seeing disabled population, while, Nanded is located in south eastern part of Maharashtra, in rain-shadow zone. Undeveloped agriculture, farmer's community and poor economic condition are the causes of poor and imbalanced diet to women and children. Mumbai is a moralboosting place of Maharashtrians. Mumbai is the source of job opportunities, business and markets hence became mainstay of blind people. In Maharashtra State there are five intensive and extensive zones of in-seeing disabled population. Out of these, two zones are found in tribal region and remaining two zones in backward agriculture, poor economic and rain-shadow zones. Out of the total population about $1 \%$ population is disabled with in-seeing. This proportion is alarming. Government of Maharashtra should take immediate actions and planning in such tribal region to provide balance diet to pregnant women.
\end{abstract}

Key words: In-seeing, disabled, intensity, concentration, and medical advice.

\section{INTRODUCTION}

As per the population census 2001, total population of Maharashtra was 9.68 corers which were $9.4 \%$ of the total population of India (http://www.census2011.co.in/ census/state/maharashtra.html; Census of India, 2011). Maharashtra is the second largest state in India in respect to population after Uttar Pradesh. The projected population of the state as on 1st March 2006 was 10.41 corers (Maharashtra, 2008). Out of the total population of the state about $57.6 \%$ population is living in 41095 villages.

Maharashtra is located in the north central part of Peninsular India, surrounded by Gujarat and Madhya Pradesh on the north and west, Karnataka and Andra Pradesh on the south and Arabian Sea in the west, covering an area of 307713 square $\mathrm{km}$. The state stretches between $15^{\circ} .44^{\prime}$ North and $22^{\circ} .10^{\prime}$ North and $72^{\circ}$ East and $80^{\circ}$ East longitudes. Maharashtra is the third largest state in India regarding the geographical area after Rajasthan and Madhya Pradesh. In the present paper an attempt is made to display district wise distribution, concentration and intensity of in-seeing disabled population.

It is learned to note that complete and partial blindness is associated with diet of pregnant women and people. This event is happening with ' $A$ ' vitamin deficiency. Most of the rural people ignore the balanced diet concept. Therefore, highest concentration and intensity of inseeing disabled population is found in rural areas as compare to urban centers (Government of Maharashtra, 2002). Mumbai is only one urban centre having huge 
Table1. Proportion of different disabled population in rural and urban areas of Maharashtra State.

\begin{tabular}{lccc}
\hline Residence & Total (\%) & Rural (\%) & Urban (\%) \\
\hline In-seeing disabled person & 37.01 & 64.70 & 35.30 \\
In speech disabled person & 7.20 & 62.64 & 37.36 \\
In hearing disabled person & 5.89 & 74.91 & 25.09 \\
In movement disabled person & 36.31 & 66.62 & 33.38 \\
Mentally retarded person & 13.59 & 58.49 & 41.51 \\
Total disabled persons & 100.00 & 65.01 & 34.99 \\
\hline
\end{tabular}

Source: Census of India 2001.

concentration, while in Amravati, Nanded, Bhandara and Gondiya tribal districts highest concentration of in-seeing disabled population is observed. Mumbai metropolitan is the main center of job opportunities. Hence blind people migrated from rural areas to Mumbai. Therefore highest concentration of in-seeing disabled population is found in Mumbai. An attempt is made to present a comparative scenario of concentration and intensity of in-seeing disabled population in Maharashtra (Shinde, 1981) with the help maps and graphs.

\section{Objectives}

The main intension of this research paper is:

1) To identify the districts having highest number of inseeing disabled population in Maharashtra state.

2) To display spatial distribution of in-seeing disabled population in the state.

3) To calculate concentration of in-seeing disabled population.

4) To identify intensity zones of in-seeing disabled population.

5) To compare the concentration of in-seeing disabled population calculated by statistical method and intensity displayed by cartographic technique.

\section{Hypothesis}

$\mathrm{H}_{1}$ : Concentration of in-seeing disabled population is more in rural areas than the urban centers.

$\mathrm{H}_{2}$ : The proportion in-seeing disabled male is comparatively higher than that of the female population.

\section{RESEARCH METHODOLOGY}

\section{Data base}

To find out the intensity and concentration of in-seeing disabled population in Maharashtra state, data of disabled population have been collected from Census Data of India.

\section{Data analysis techniques}

This research work is entirely completed with the help of computer. For the analysis of population data the following techniques have been used.

1) To extract the data, "advanced filter" command of M.S. Excel worksheet is used.

2) To filter the data "IF condition" command is used to classify the data into different groups to prepare the maps.

3) Concentration Index is calculated with the help of following equation.

\section{Concentration Index= st/ST}

$\mathrm{S}=$ In-seeing disabled population in the district.

$\mathrm{t}=$ Total disabled population of the district

$\mathrm{S}=$ Total in-seeing disabled population of Maharashtra state

$\mathrm{T}=$ Total disabled population of Maharashtra State

4) To find out district wise intensity of in-seeing disabled population following cartographic technique is used.

a) Dot map showing district wise in-seeing disabled population is prepared.

b) On the dot map, $(100 * 100 \mathrm{~km}) 10000 \mathrm{~km}^{2}$ grids are supper imposed through layer command given in Auto CAD Map- GIS software.

c) Dots in each grid are counted and counted figures are placed in respective grid through property command of Auto CAD Map.

d) Considering the values of grids, isopleths are drawn and hatched according to intensity.

e) Concentration and intensity of in-seeing disabled population is compared to each other.

\section{DISCUSSION}

As per the census record of Maharashtra state 2001, about 1569582 persons are disabled by all types of disability, which contributes $1.62 \%$ of the total population of the state. Disabled population comprises in-seeing, in speech, in-hearing, in movement and in-mental population. Table 1 shows the different disabled population in rural and urban areas during 2001.

Table 1 sows that out of the total disabled population about $65 \%$ disabled population are observed in rural villages, which is two times more than the disabled population in urban areas. Out of the total disabled population about $73.32 \%$ was contributed by in-seeing and inmovement disabled population. Among the disabled 
Table 2. Sexwise proportion of in-seeing disabled population 2001.

\begin{tabular}{lcc}
\hline Residence & Male & Female \\
\hline Total & 55.16 & 44.84 \\
Rural & 53.64 & 46.36 \\
Urban & 57.96 & 42.04 \\
\hline
\end{tabular}

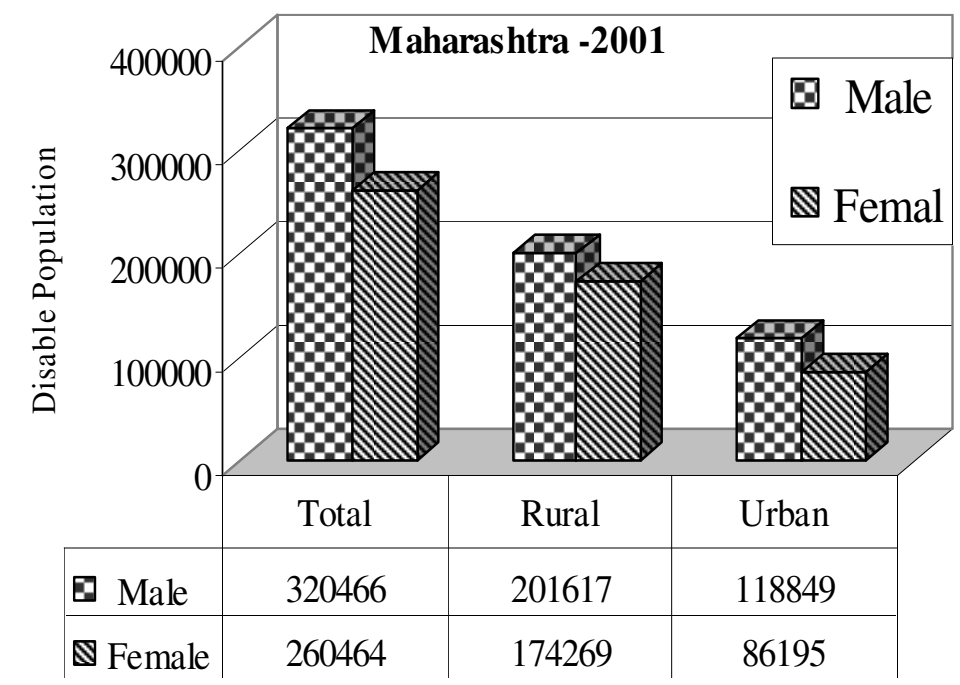

Figure 1. In seeing disable population in Maharashtra-2001.

population, in-seeing disabled persons are ranked first. (37.01\%) The proportion of in-seeing disabled population in rural areas is found significant $(64.70 \%)$. Table 1 also clears the fact that all types of disabled population are found significant in rural areas as compare to urban centers. It is clear that in-seeing and in-movement disability is a serious and alarming problem in Maharashtra. In the present work only in-seeing disabled population is considered.

\section{In-seeing disabled population}

As per the census record, about 580930 persons are found in-seeing disabled in Maharashtra State. Table 2 shows sex wise proportion of in-seeing disabled population. In rural areas out of the total in-seeing disabled population, about $53.64 \%$ males are disabled with inseeing. While in urban area about $57.96 \%$ males are disabled. This table clears that number of in-seeing disabled males are found more than the females in both rural and urban areas.

Figure 1 shows sex wise male and female in-seeing disabled population. Figure 1 clearly shows that males are more exposed to blindness than the females. In both rural and urban areas numbers of in-seeing disabled males are found more.
Spatial distribution of in-seeing disabled population Map 1 is showing district wise proportion of in-seeing disabled population to total disabled population. This map shows that Nandurbar and Nanded districts have highest proportion of in-seeing disabled population (55.85 and $52.98 \%$ respectively). Nandurbar is a tribal district having more than $60 \%$ scheduled tribes' population. Most of geographical area is occupied by Satpura ranges. Due to malnutrition and imbalanced diet of children and pregnant women, proportion of in-seeing disabled population is significant there. Out of the total population of the district about $1.00 \%$ populations are victim of blindness. Nanded district is located in south eastern part of Maharashtra state. This district ranks first in the state regarding the proportion of in-seeing disabled population to total population. Approximately $1.42 \%$ to total population is found affected by blindness. In this district most of the villages are economically backward. About $90 \%$ population belongs to farmer community. They also ignore the concept of balance diet. This might be a major cause behind such high proportion of blind cases.

Mumbai and Mumbai suburban have also highest proportion of in-seeing disabled population (51 to 54\%). Out of the total population about 0.68 and $0.84 \%$ of total population is in-seeing disabled. Due to availability of job opportunities in Mumbai and Mumbai suburban areas, most of in-seeing disabled population were migrated from 


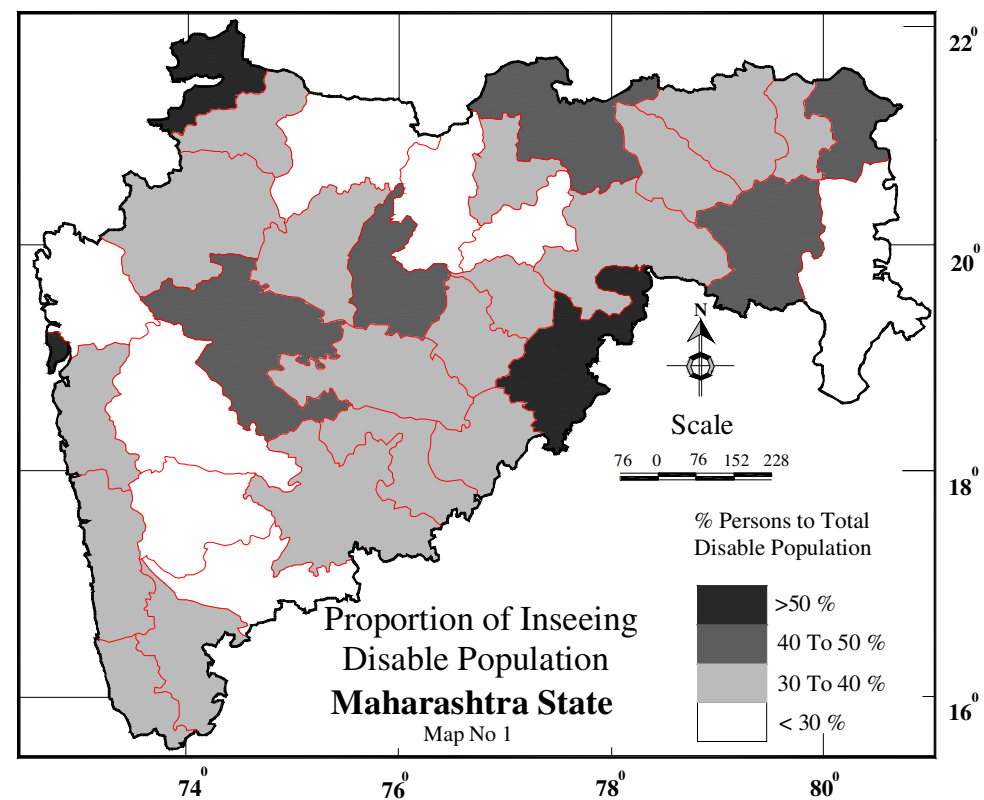

Map 1. District wise proportion of in-seeing disabled population to total disabled population.

Source: Census of India 2001.

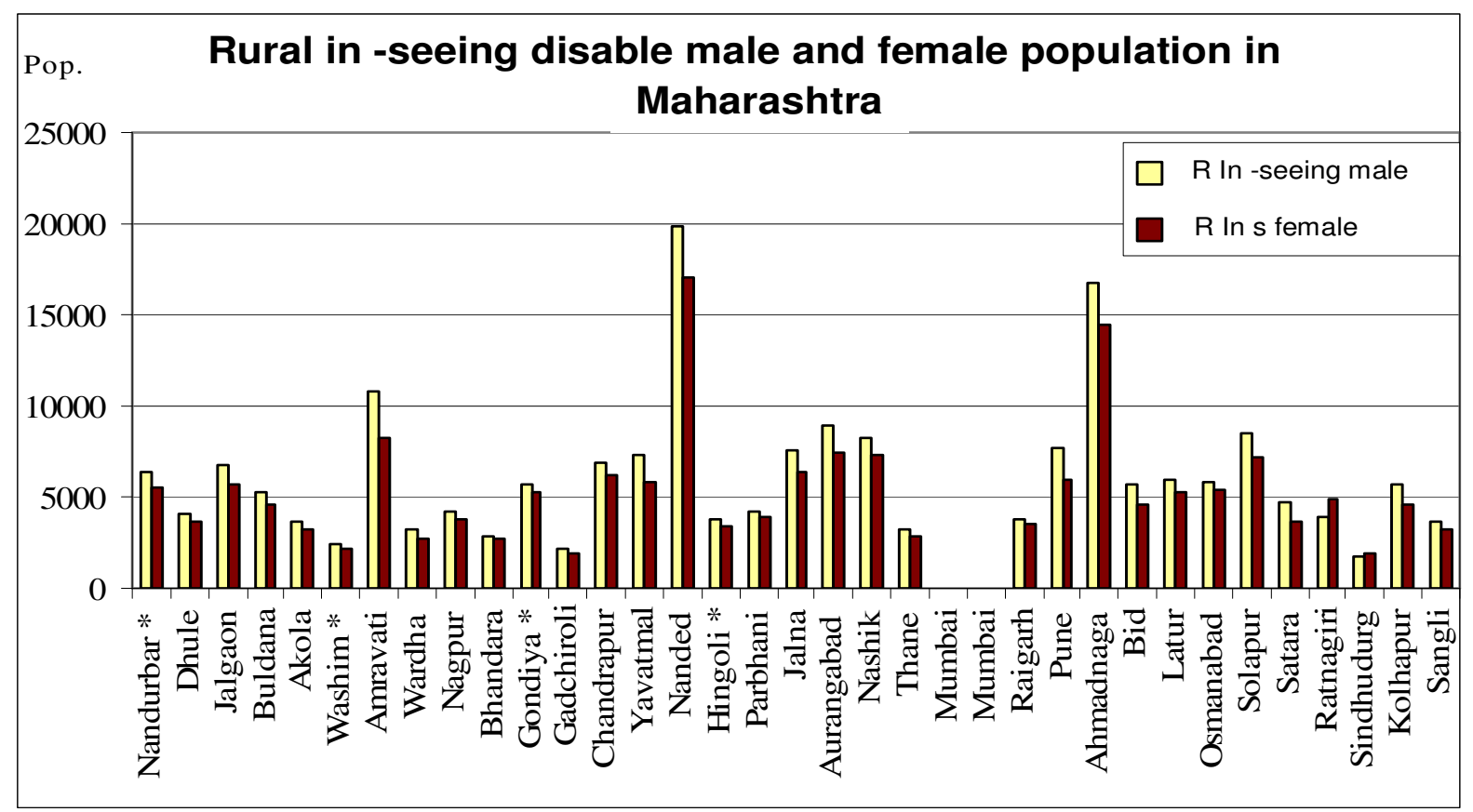

Figure 2. Rural in -seeing disable male and female population in Maharashtra.

rural to urban areas. Amravati, Gondia, Chandrapur are tribal districts. In this region, out of the total disabled population about 42 to $45 \%$ population is disabled by inseeing. Jalana and Ahmednagar districts have also more than $42 \%$ in-seeing disabled population. Remaining all districts have less than $30 \%$ of in-seeing disabled population in Maharashtra.

Map 2 reveals the spatial distribution of in-seeing disabled population. On this dot map $10000 \mathrm{sq} \mathrm{km}$ grids are superimposed and dots are counted in respective grids. 


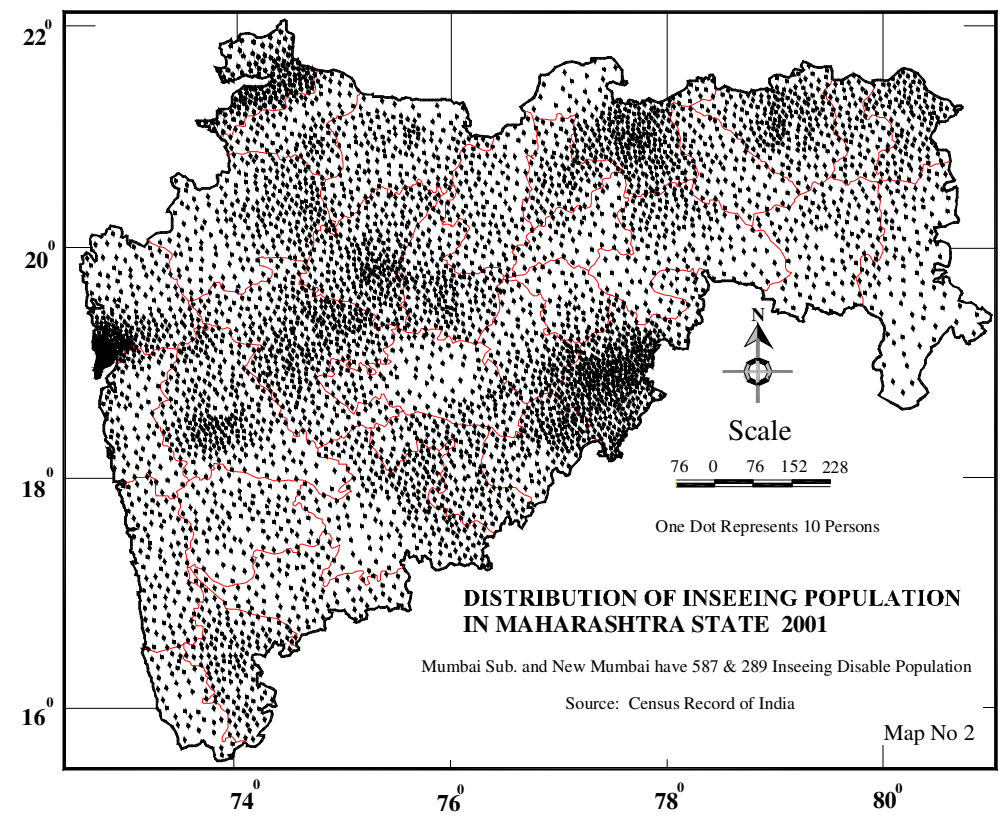

Map 2. Spatial distribution of in-seeing disabled population. Source: Census of India 2001.

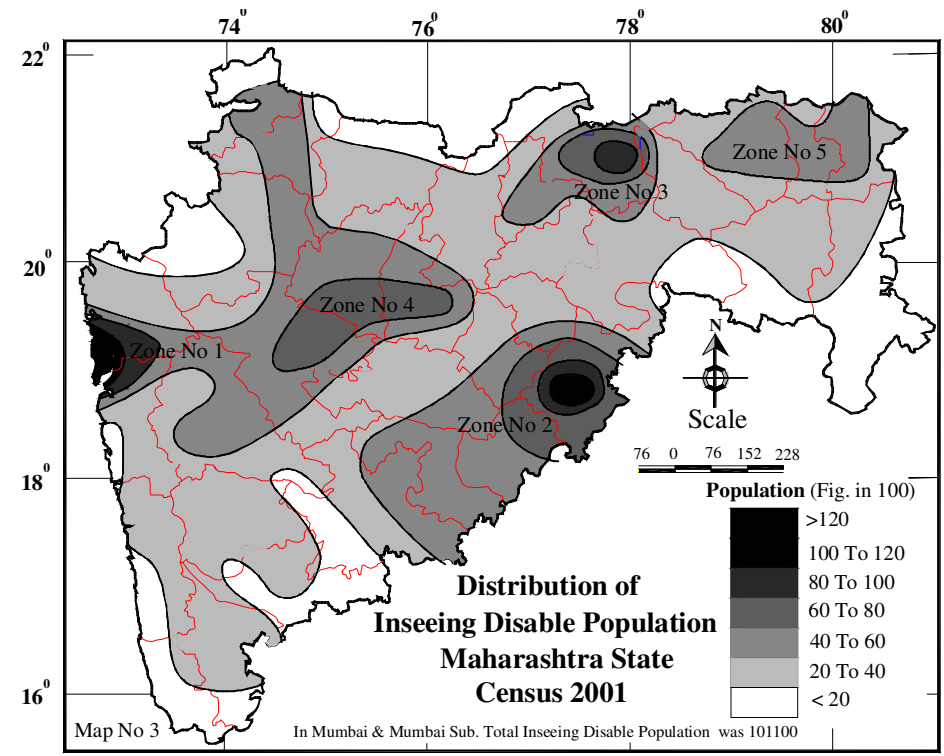

Map 3. Isopleth map.

Source: Census of India 2001.

With the help of counted figures isopleths are drawn. Thus dot map is transformed into isopleth map (Map 3). According to intensity of in-seeing disabled population five intensive zones are demarcated. This map clears the fact that zone number 2 and 5 are tribal districts. While, zone number 3 and 4 are economically backward and rain shadow. In zone number 1 (Map 2) world-ranking metropolitan centers are located those are providing job opportunities to blind people. Hence, most intensive zone of in-seeing disabled is found there.

\section{District wise in-seeing disabled male and female population in rural areas}

Figure 2 shows that in rural areas of Nanded and 


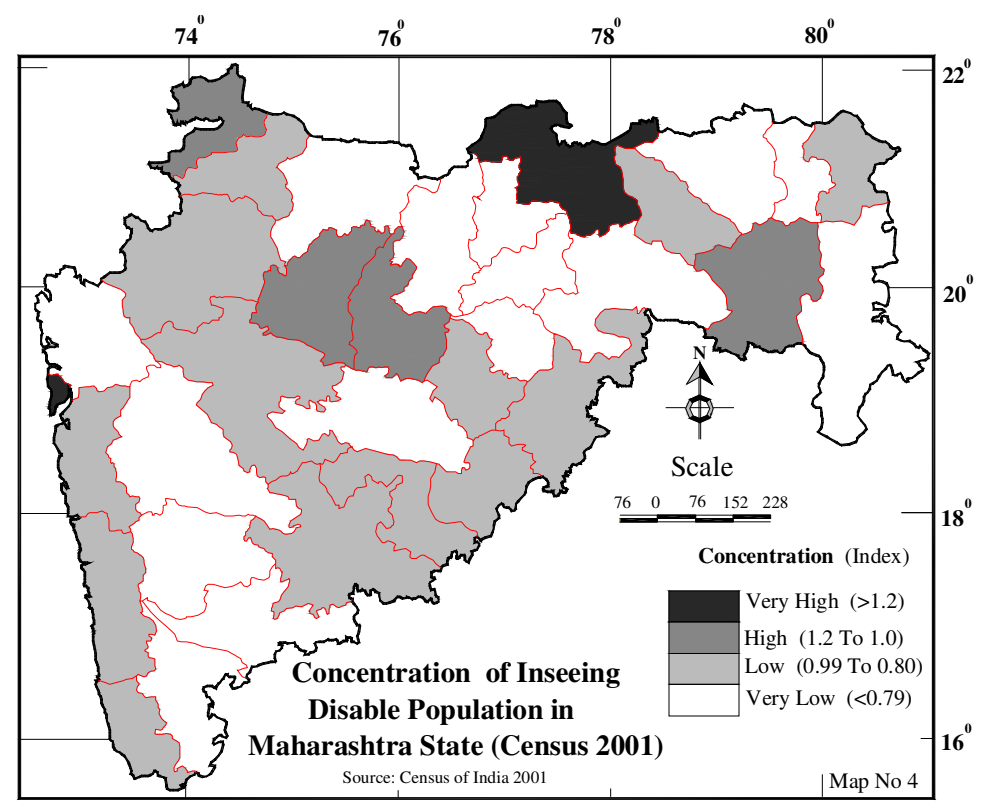

Map 4. Concentration of in-seeing disabled population. Source: Census of India 2001.

Table 3. Comparison between concentration calculated by statistical method and intensity displayed by cartographic technique.

\begin{tabular}{ll}
\hline $\begin{array}{l}\text { Results of map showing concentration of in- } \\
\text { seeing disabled population }\end{array}$ & $\begin{array}{l}\text { Results of map showing Intensity of in-seeing disabled } \\
\text { population }\end{array}$ \\
\hline $\begin{array}{l}\text { Highest concentration is found in Mumbai, and } \\
\text { Mumbai suburban areas. }\end{array}$ & $\begin{array}{l}\text { Highest intensity is observed in Mumbai and Mumbai } \\
\text { suburban areas }\end{array}$ \\
$\begin{array}{l}\text { Medium concentration is found in Nandurbar and } \\
\text { Chandrapur districts }\end{array}$ & $\begin{array}{l}\text { Medium Intensity is found in Nanded Amravati, Gondia, } \\
\text { Bhandara, southern Jalana and Aurangabad districts. }\end{array}$ \\
Low concentration is observed in remaining districts. & Low intensity is found in remaining districts \\
\hline
\end{tabular}

Ahmednagar districts, highest number of in-seeing disabled population is observed. It is to noted that all districts except Sindhudurg, number of in-seeing males are more than females. In Nanded and Amravati districts the proportion of male disabled is comparatively more than that of females.

Map 4 shows the concentration of in-seeing disabled population. The results of concentration index shown in the map show that, Mumbai and Amravati districts have highest concentration of in-seeing disabled population followed by Aurangabad, Jalna and Nagpur. Comparison between Concentration calculated by statistical method and intensity displayed by cartographic technique is shown in the Table 3.

Comparative scenario of concentration and intensity of in-seeing disabled population shows that cartographic technique of intensity has given more accurate and detailed results than that of the concentration method.

\section{Conclusion}

Maharashtra is located near the heart land of Peninsular India, which is the third largest state in India regarding the geographical area and second largest state in respect to population. As per the census of India about 1.62\% population of Maharashtra state is found disabled. In the disabled population in-seeing disabled persons ranked first, constituting $37.01 \%$ of the total disabled population. It is observed that in rural areas, proportion of in-seeing disabled population is near about two times more than that of the urban areas. The proportion of in-seeing disabled males is significantly higher than that of the females.

Spatial distribution in terms of concentration and intensity of in-seeing disabled population in Maharashtra state varies from district to district. Highest proportion and intensity of in-seeing disabled population is observed in 
Nandurbar and Nanded districts. Nandurbar is a tribal district located in Satpura mountainous region. Poor economic condition, mountainous region, imbalance diet to pregnant women and children are the important causes of high proportion of in-seeing disabled population, while, Nanded in southeastern district is located in rain shadow zone. Undeveloped agriculture, farmer's community and poor economic condition are the causes of poor and imbalanced diet to pregnant women and children. Mumbai is a moral-boosting place and source of job opportunities due to availability of, business and markets hence became mainstay of blind people.

In the state there are five intensive and extensive zones of in-seeing disabled population. Out of these, two zones are found in tribal region and remaining two zones in backward agriculture, poor economic and rain-shadow zones. Out of the total population about $1 \%$ population is disabled with in-seeing. This proportion is quite significant. Government of Maharashtra should take immediate actions so that balance diet should be provided to pregnant women for eradication of this kind of disability. Central government has effectively implemented the programme to eradicate pulse polio.

Along with this program diet survey of pregnant women and children should be launched with the financial support of United Nations International Children's Emergency Fund (UNICEF), World Health Organization (WHO) and Child Care Organization. As human resource is an asset and wealth of nation. Such precautionary measures are more welcoming.

\section{REFERENCES}

Census of India (2011). Government of India. 31 March 2011. Retrieved 6 April 2011.

Government of India (2001). Census Hand Book of India. Published by Govt. of India.

Government of Maharashtra (2002). Human Development Report Maharashtra. Typeset and printed by Government Central Press, Netaji Subhash Road, Charni Road, Mumbai 400004.

http://www.census2011.co.in/census/state/maharashtra.html

Maharashtra. Countries. India: World Bank. Retrieved 2008-10-31.

Shinde SD (1981). A Spatial Analysis of Rural Population of Maharashtra State. The Deccan Geographer, Secunderabad. 19(2\&3). 